\title{
Pinoresinol reductase 1 impacts lignin distribution during secondary cell wall biosynthesis in Arabidopsis
}

Qiao Zhao', Yining Zeng ${ }^{2,6}$, Yanbin Yin $^{3}$, Yunqiao Pu ${ }^{4,6}$, Lisa A. Jackson ${ }^{1,6}$, Nancy L. Engle $^{6,7}$, Madhavi Z. Martin ${ }^{6,7}$, Timothy J. Tschaplinski ${ }^{6,7}$, Shi-You Ding ${ }^{2,6}$, Arthur J. Ragauskas $^{4,6}$, and Richard A. Dixon ${ }^{1,5,6 *}$

${ }^{1}$ Plant Biology Division, Samuel Roberts Noble Foundation, 2510 Sam Noble Parkway, Ardmore, OK 73401, USA

${ }^{2}$ Biosciences Center, National Renewable Energy Laboratory, Golden, CO 80401, USA

${ }^{3}$ Department of Biological Sciences, Northern Illinois University, DeKalb, IL 60115, USA

${ }^{4}$ Institute of Paper Science and Technology, Georgia Institute of Technology, Atlanta, GA, USA

${ }^{5}$ Present address: Department of Biological Sciences, University of North Texas, 1155 Union Circle \#305220, Denton, TX 76203-5017, USA

${ }^{6}$ BioEnergy Science Center (BESC), Oak Ridge National Laboratory, Oak Ridge, Tennessee 37831

${ }^{7}$ Biosciences Division, Oak Ridge National Laboratory, Oak Ridge, Tennessee 37831

*For correspondence: Richard A. Dixon. e-mail Richard.Dixon@unt.edu; phone +1-940-5652308, University of North Texas, Department of Biological Sciences, 1155 Union Circle \#305220, Denton, TX 76203-5017 


\section{ABSTRACT}

Pinoresinol reductase (PrR) catalyzes the conversion of the lignan (-)-pinoresinol to (-)lariciresinol in Arabidopsis thaliana, where it is encoded by two genes, $\operatorname{PrR} 1$ and $\operatorname{PrR} 2$, that appear to act redundantly. PrRl is highly expressed in lignified inflorescence stem tissue, whereas $\operatorname{Pr} R 2$ expression is barely detectable in stems. Co-expression analysis has indicated that PrRl is co-expressed with many characterized genes involved in secondary cell wall biosynthesis, whereas $\operatorname{PrR} 2$ expression clusters with a different set of genes. The promoter of the PrRl gene is regulated by the secondary cell wall related transcription factors SND1 and MYB46. The loss-of-function mutant of PrRlshows, in addition to elevated levels of pinoresinol, significantly decreased lignin content and a slightly altered lignin structure with lower abundance of cinnamyl alcohol end groups. Stimulated Raman scattering (SRS) microscopy analysis indicated that the lignin content of the prrl-1 loss-of-function mutant is similar to that of wild-type plants in xylem cells, which exhibit a normal phenotype, but is reduced in the fiber cells. Together, these data suggest an association of the lignan biosynthetic enzyme encoded by $\operatorname{PrRl}$ with secondary cell wall biosynthesis in fiber cells.

\section{KEY WORDS}

Lignan, lignin, interfascicular fiber, mutant, stimulated Raman scattering microscopy

\section{Introduction}

Lignans are dimers derived from the stereospecific oxidative coupling of hydroxycinnamyl alcohols. The initial step of lignan dimerization is mediated by an oxidase (eg. laccase) acting in concert with a dirigent protein that confers enantio-selectivity to the free radical-derived coupling (Davin et al., 1997). Approximately 3,000 different lignans are widely distributed in the plant kingdom (Schmidt et al., 2010). The numerous beneficial effects of lignans on human health, via estrogenic and anticancer activities, are well documented (Dixon, 2004; McCann et al., 2005). However, the exact roles of lignans in planta remain elusive although it has been hypothesized that they are involved in plant defense (Naoumkina et al., 2010).

The most characterized lignans are the group with $9\left(9^{\prime}\right)$-oxygen linkages (Umezawa, 2003). This class of lignans arises from the enantio-selective dimerization of two coniferyl alcohol units (1) to give rise to pinoresinol (2). Pinoresinol is then sequentially reduced to 
lariciresinol (3) and secoisolariciresinol (4) by a bi-functional pinoresinol/lariciresinol reductase (PLR) (Nakatsubo et al., 2008; Umezawa, 2003). Because of its stereo-selectivity, PLR is suggested to have enantiomeric control on the lignan biosynthetic pathway even though the dirigent protein is considered to be the asymmetric inducer (von Heimendahl et al., 2005). Conventional PLRs can utilize both pinoresinol and lariciresinol as substrates (i.e. are bifunctional) (Hano et al., 2006; von Heimendahl et al., 2005). However, in Arabidopsis thaliana, the two pinoresinol reductase enzymes show only weak or no activity toward lariciresinol, and are therefore named PrR1 and PrR2 rather than PLR (Nakatsubo et al., 2008).

PLR genes have organ-specific expression patterns. In flax (Linum usitatissimum), genes encoding two PLRs with different enantiospecificity have been cloned. Both LuPLRI and LuPLR2 are expressed in flax seed tissues, whereas only LuPLR2 is expressed in stem and leaf tissues (Hemmati et al., 2010). In Arabidopsis, both PrR1 and PrR2 catalyze pinoresinol reduction in a redundant manner in root tissue, where lignans are mostly accumulated, but only PrR1 is active in stem tissue (Nakatsubo et al., 2008).

The basic unit of pinoresinol, coniferyl alcohol, is also shared by the lignin biosynthesis pathway. Lignin is the second most abundant biopolymer on earth, and a major component of plant secondary cell walls. It is derived from three major subunit precursors; so-called $\mathrm{H}(p$ coumaryl alcohol), G (coniferyl alcohol) and S (syringyl alcohol) monolignols (Bonawitz and Chapple, 2010; Zhao and Dixon, 2011). Even though coniferyl alcohol is the common unit of both lignin and lignans, there is no evidence that lignans per se are components of the plant wall structure. It is also not clear how plants allocate coniferyl alcohol for the biosynthesis of lignans versus lignin.

Recently, it has been shown in both flax and pine that the lignan-related gene PLR is upregulated along with cell wall biosynthetic genes in highly lignifying stem tissues or during compression wood formation (Huis et al., 2012; Villalobos et al., 2012). Furthermore, a comparison of co-expressed gene networks with primary and secondary wall cellulose synthases in a variety of different plant species identified gene families that are consistently co-regulated with cellulose biosynthesis; among these genes was PrRl (Ruprecht et al., 2011). Because Arabidopsis PrR1 is only expressed highly in mature stem tissue, we have further investigated the potential role of this gene in cell wall biosynthesis. Our results confirm that PrRl is coexpressed with secondary cell wall biosynthetic genes, indicate directly that $\operatorname{Pr} R 1$ is regulated by 
regulators of secondary cell wall formation, and show that loss of function of $\operatorname{PrRl}$ results not only in changes in lignin levels, but also in alterations in lignin structure and tissue-specific lignin distribution.

\section{Results}

\subsection{Differential expression of PrR1 and PrR2 in Arabidopsis.}

The different gene expression patterns of $\operatorname{PrR} 1$ and $\operatorname{Pr} 22$ were confirmed by analysis of microarray expression data from the Arabidopsis eFP Browser; PrRl transcripts are expressed in most tissues, with highest level in the lignified second internodes (Fig. S1), whereas PrR2 transcript levels are high in root tissues, where most lignan accumulates, with almost no transcripts detectable in the $2^{\text {nd }}$ internode (Fig. S2).

To investigate genes which are co-expressed with $\operatorname{PrR} 1$ and $\operatorname{PrR} 2$, we examined the recently built cell wall co-expression database (http://csbl.bmb.uga.edu/publications/materials/shanwang/CWRPdb/index.html; Wang et al., 2012). A bi-clustering analysis of Arabidopsis microarray data with a focus on cell wall-related genes was applied to build co-expressed gene modules. In each module graph, the node is shown

as a yellow diamond (known/annotated cell wall-related genes), an aquamarine square (known/annotated transcription factor gene) or a red circle (other genes); an edge connecting two nodes means that these two genes are co-expressed (Fig. 1). Similar co-expression graphs are also available in the ATTED-II database (http://atted.jp/data/locus/At4g13660.shtml), which uses different methods for clustering microarray data and calling co-expression modules.

Based on this analysis, PrRl is co-expressed with many characterized cell wall-related genes represented by yellow diamonds and aquamarine squares (Fig. 1). For instance, LAC17 is a laccase that has been directly implicated in lignin biosynthesis (Berthet et al., 2011); cellulose synthase-like A9 (CSLA9) is a beta-mannan synthase involved in hemicellulose biosynthesis (Davis et al., 2010); cellulose synthase A7(CesA7) is involved in cellulose synthesis and MYB46 is a transcriptional master switch of secondary cell wall formation (Zhong et al., 2007). These data confirm the co-expression of $\operatorname{PrRl}$ with CesA genes as previously reported (Ruprecht et al., 2011). In contrast, $\operatorname{Pr} R 2$ clusters with a totally different set of genes, including a laccase that has not been implicated in lignin polymerization, one peroxidase that has been implicated in lignin biosynthesis (Fig. 1; Table S1) and a protein associated with casparian strip formation, a process 
which involves peroxidase-mediated lignification in specific cell types in the root (Lee et al., 2013).

\subsection{PrR1 is regulated by the secondary cell wall transcription factors SND1 and MYB46}

To investigate whether PrRl is under the control of secondary wall transcription factors, we used an Arabidopsis leaf protoplast-based promoter trans-activation system. Protoplasts were transfected with a construct in which firefly luciferase (reporter) is driven by the promoter consisting of a 1kb DNA fragment upstream of the start codon of PrR1. SND1 and MYB46 were chosen as potential trans-activators for this assay since both are known to be master switches of the entire secondary cell wall biosynthetic program (Zhong et al., 2006; Zhong et al., 2007). Coexpression of cauliflower mosaic virus (CaMV) 35S promoter driven SND1 or MYB46 activated the expression of the firefly luciferase reporter gene driven by the $\operatorname{PrRl}$ promoter by around 30fold (Fig. 2).

\subsection{Loss of function of PrRl affects both lignan and lignin biosynthesis}

The prr1-1 knock-out mutant SALK_058467 was obtained from the ABRC at Ohio State University (http://abrc.osu.edu/) (Nakatsubo et al., 2008). This line contains a T-DNA insertion within an exonic region of the PrRl gene. Mature inflorescence tissue was harvested and subjected to metabolite profiling by gas chromatography-mass spectrometry (GC-MS). The results (Table 1) indicate that the concentration of the lignan, pinoresinol, was 4.8-fold higher in the loss-of-function prrl mutant than in control plants. At the same time, the concentrations of sinapic acid and its conjugation storage product, sinapoyl-malate, were reduced to $80 \%$ and $50 \%$ of the control, respectively. The putative product of PrR1, lariciresinol, was not present at detectable levels in any of the plant lines. Although the vast majority of metabolites were not altered in prrl, a limited number of nitrogenous metabolites were reduced $17-29 \%$, including ethanolamine, glutamine, and $\beta$-alanine, Whereas sinapic acid was modestly reduced in the lossof-function mutant, it was increased (1.36-fold) in the PrR1 over-expression line, as was dehydroconiferyl alcohol (another lignan), 4- $O$-Glucopyranosyl-vanillic acid (1.26 x) and three coniferyl alcohol-derived unidentified lignans (eluting at 16.48, 16.53, and $17.17 \mathrm{~min}, \sim 1.4 \mathrm{x}$ ). These data are consistent with a role for PrR1 in lignan biosynthesis in the Arabidopsis stem. 
The metabolite responses observed in the over-expression mutant suggest a more generalized function in the production of guaiacyl-derived lignans.

Next, lignin content and composition of the prrl loss-of-function mutant were determined. Thioacidolysis analysis, which measures primarily $\beta$ - $O$-4-linked monolignol units, revealed that the mutant had a small but significant reduction in thioacidolysis yield compared to the wild-type (Fig.3), with similar reductions in the proportions of both $\mathrm{G}$ and $\mathrm{S}$ monolignol units.

To further compare lignin composition in the prrl loss-of-function mutant and wild type, lignin was extracted and subjected to nuclear magnetic resonance spectroscopy. Analysis of ${ }^{13} \mathrm{C}$ ${ }^{1} \mathrm{H}$ HSQC spectra revealed similar carbon-proton correlation signals patterns in both the aromatic and aliphatic regions of the lignin from the wild type and prrl mutant, indicative of no significant changes in lignin core structures (Fig. 4). The aromatic carbons in syringyl and guaiacyl units were readily observed with the presence of their diagnostic correlation signals around 103.8/6.67 $\left(\mathrm{S}_{2 / 6}\right), \quad 110.5 / 6.94\left(\mathrm{G}_{2}\right), 114.8 / 6.88\left(\mathrm{G}_{5}\right)$, and 118.6/6.81 $\left(\mathrm{G}_{6}\right) \mathrm{ppm}$, respectively. Substructures A-E (Fig. 4) were evidently detected in the lignin from both wild type and prrl mutant, with $\beta-O-4$, phenylcoumaran and resinol being the major inter-linkage subunits. The semiquantitative analysis of subunit contours in HSQC spectra showed that the lignin in the mutant appeared to have a slightly higher relative abundance of $\beta-O-4$ linked subunits (A in Fig.4). More clearly, the signal intensities of dibenzodioxocin and cinnamyl alcohol end groups were notably decreased in the prrl mutant.

\subsection{Impact of loss of function of PrRl on the cellular distribution of lignin.}

The above analyses of lignin determined the thioacidolysis yield and composition of the polymer in the bulk lignin, i.e. the sum of the lignin from all cell types. The SND1 transcription factor that regulates PrR1 primarily controls lignification in interfascicular fibers (Zhao et al., 2010a; Zhong et al., 2006). We therefore reasoned that additional information on the impacts of loss of $\operatorname{PrR} 1$ function on lignification could be obtained by examination of tissue-specific changes in lignin composition. We have previously employed laser capture microdissection for this purpose in the model legume Medicago truncatula (Nakashima et al., 2008). However, this approach is extremely time-consuming. We therefore decided to use two-color stimulated Raman scattering

microscopy (SRS), which has been utilized for in situ quantification of lignin and 
polysaccharides at both the tissue- and cell-specific level (Ding et al., 2012). Under the light microscope, the cell size and cell wall thickness of secondarily thickened cells in the second internode of the stem appear to be similar in wild type and mutant. The lignin contents of xylem fibers and vessel cells were imaged using SRS microscopy and the average lignin intensities were compared (Fig. 5A and B). Interestingly, the mutant exhibits a significant reduction in lignin content in the fibers, but not in the vessel cells, as seen when lignin distribution across the cell wall is presented as pixel intensity and normalized to the sum of all intensities (Fig. 5C). In xylem vessels, the lignin distribution is similar in wild-type and mutant plants (Fig 5A), whereas in xylem fibers, the lignin signal peak shifted to lower intensity and narrower intensity distribution across the cell wall in the mutant compared with wild type (Fig. 5B). Analysis of SRS signals across larger cross-sectional areas of the first, second and third internodes of the inflorescence stems did not reveal an increase in collapsed xylem vessels, as previously reported for this mutant (Ruprecht et al., 2011) (Fig. S3).

Total cell wall carbohydrate content was also compared between the mutant and wild type using two-color SRS microscopy. In both fibers and vessel cells, the mutant has a reduced level of carbohydrate, and the difference is more striking in fibers (Fig. 5D).

\subsection{Changes in gene expression as a result of altering PrR1 expression.}

The lignan dehydrodiconiferyl alcohol has been ascribed a role in the control of plant development, specifically as a regulator of cell division (Binns et al., 1987). It is therefore possible that the observed impacts of modification of $\operatorname{PrR} 1$ expression on cell wall composition/structure could be secondary effects resulting from altered plant development rather than direct effects associated with lignin precursor synthesis. If PrR1 were involved in the biosynthesis of a lignan metabolite with a regulatory function, it is likely that loss of $\operatorname{PrR} 1$ function would have an impact on many genes controlled by that regulator. To determine whether loss of function of $\operatorname{PrRl}$ causes major changes in gene expression, we performed microarray analysis. Compared with wild type, only very few genes are up-regulated or downregulated by over two-fold as a result of PrRl disruption. Among those, only one gene (At3g44990, encoding a xyloglucan endo-transglycosylase), has a functionally identified role in cell wall biosynthesis (Table S2), and none of the genes was strongly up- or down-regulated. We also examined the effects of over-expression of PrR1 by microarray analysis. A four-fold over- 
expression of PrR1 was associated with over two-fold expression of 59 genes, none of which appeared to be directly associated with cell wall biosynthesis (Table S3). In fact, the majority of the up-regulated genes were annotated as being involved in abiotic stress responses (Table S3). Note that the extent of up-regulation of genes as a result of $\operatorname{PrRl}$ over-expression was, overall, much greater than in response to loss of function of PrR1 (Tables S2 and S3).

\section{Discussion}

Lignin is a phenylpropanoid polymer that serves as one of the major secondary cell wall components. Dimerization of two units of the lignin monomer, coniferyl alcohol, gives rise to pinoresinol, a simple lignan with $9\left(9^{\prime}\right)$-oxygen linkages. Pinoresinol is then sequentially reduced to lariciresinol and secoisolariciresinol by a bi-functional pinoresinol/lariciresinol reductase (PLR) (Nakatsubo et al., 2008; Umezawa, 2003). PLR/ PrR genes have organ-specific expression patterns. In Arabidopsis, PrR1and PrR2 redundantly catalyze the reduction of pinoresinol in roots. PrR2 is root-specific and PrR1 is expressed highly in both roots and aerial tissues (Nakatsubo et al., 2008). Pinoresinol levels in aerial tissue increase following loss of function of PrRl, indicating that PrRl plays a role in lignan biosynthesis in aerial tissue and has not, therefore, undergone complete neofunctionalization, and the observation that over-expression of PrR1 results in over-production of lignans other than lariciresinol indicates that the gene has a more generalized effect on lignan production than previously known. It is also interesting that both this study and a previous one (Ruprecht et al., 2011) show that lignin content is decreased when PrRI expression is disrupted. In fact, lignin content might be expected to be increased when lignan biosynthesis is compromised, considering the potential for competition between the lignin and lignan pathways. Therefore, it is possible that lignan or "lignan-like" compounds may somehow be involved in lignin polymerization, consistent with the fact that $\operatorname{Pr} R 1$ is co-expressed with genes involved in secondary wall biosynthesis, especially the lignin laccase LAC17. No other lignin biosynthetic genes appear to co-express with $\operatorname{PrR} 1$, suggesting that the biosynthetic pathways to monolignols and lignans are independently regulated. Some types of lignans might be incorporated into lignin polymers with the help of the lignin laccase LAC17. However, with current technology, it is very hard to detect in situ lignan deposition into lignin polymers. Furthermore, it seems unlikely that initial formation of lignan-like units is an early critical step in lignin polymerization, because, unlike the dramatic loss of lignin phenotype observed in 
Arabidopsis, following loss of function of the three laccase genes LAC4, LAC11 and LAC17 (Zhao et al., 2013a), loss of function of $\operatorname{PrRl}$ has only a small impact on lignin quantity. This small reduction in overall lignin quantity, accompanied by altered lignin distribution across the walls of fiber cells, would not be expected to result in gross changes in vascular morphology, unless a critical sub-fraction of the lignin polymer were being affected. It is therefore not clear why a previous report indicated that loss of function of PrR1 results in an increased percentage of distorted xylem vesssels in Arabidopsis (Ruprecht et al., 2011), an observation that we could not replicate under the growth conditions used in the present work.

Although lignans and lignins share the same building blocks, they are assembled differently. For example, lignin linkage formation mostly involves the 4-hydroxyl of monolignols, but the majority of lignan dimers are joined by $\beta-\beta$ linkages (Weng and Chapple, 2010). Lignan dimerization is considered to be an enantioselective radical coupling reaction (Davin et al., 1997), in contrast to the overall achiral process of lignin polymerization. The different linkage types in lignans and lignins suggest that there may be different oxidase enzymes involved in the respective polymerization steps. Lignans appeared earlier than lignin during evolution of plants, as they can be found in some bryophytes (Scher et al., 2003; Umezawa, 2003), whereas no solid evidence supports the presence of lignin polymers in bryophytes (Weng and Chapple, 2010). Coincidently, a phylogenetic analysis of laccases indicated that the ligninspecific laccases appear to be seed-plant specific (Zhao et al., 2013a).

The occurrence of phenylpropanoid metabolism is considered to be critical in the initial move of the aquatic ancestors of current plants onto land. Even though sporadic literature reports indicate that the biosynthesis of lignin-like compounds can be tracked back to non-vascular plants, the presence of lignin in mosses is still an open question, not to mention aquatic algal species (Weng and Chapple, 2010). However, moss cell walls contain polysaccharides with very similar composition to those of vascular plants, even though there are only trace amounts of lignin attached (Roberts et al., 2012). This raises the possibility that, in non-vascular plants, lignans may have been integrated into cell walls before the appearance of lignin, and this may represent an early step towards the evolution of lignification of secondary cell walls. This could explain the co-expression of $\operatorname{PrRl}$ with secondary cell wall biosynthetic genes. Alternatively, association of lignans with cell walls could be viewed as a purely defensive function. 
Recently, it has been shown that biosynthesis of lignans and oligolignols can accompany secondary cell wall biosynthesis in both angiosperms and gymnosperms (Huis et al., 2012; Villalobos et al., 2012). Furthermore, a study using lignan-derived antibodies immunolocalized lignans in the secondary walls in flaxseed (Attoumbre et al., 2010). Clearly, both quantitative and qualitative differences in lignin deposition are linked to disruption of a critical lignan biosynthetic gene, PrR1. Because Arabidopsis accumulates most lignans in root tissue, the rootspecific gene $\operatorname{Pr} R 2$ is functionally redundant with $\operatorname{Pr} R 1$ in roots as regards to lignan biosynthesis (Nakatsubo et al., 2008), and we have here shown that PrR2 co-expresses with two genes potentially involved in casparian strip formation in the root, it will be interesting to investigate whether there are cell wall phenotypes in root tissue when both $\operatorname{Pr} R$ genes are not functional.

\section{Experimental}

\subsection{Plant growth conditions}

Arabidopsis plants were grown in MetroMix 350 soil under $16 \mathrm{~h}$ light/ $8 \mathrm{~h}$ dark cycles at $23^{\circ} \mathrm{C}$ during the day and $21^{\circ} \mathrm{C}$ during the night $70-80 \%$ relative humidity, and $150 \mu \mathrm{mol} \mathrm{m}{ }^{-2} \mathrm{sec}^{-1}$ light intensity.

\subsection{Plant materials}

The prr1-1 mutant SALK_058467 and the prr2-1 mutant SALK_123621 were obtained from the ABRC at Ohio State University (http://abrc.osu.edu/).

\subsection{Determination of lignin composition}

Mature stems from 6 week old plants were harvested for lignin analysis using previously published procedures (Zhao et al., 2013b).

\subsection{Metabolite profiling analysis}

Fast-frozen shoot samples of two replicates each of the prr1-1 loss-of-function mutant, the PrR1 overexpressor line, and wild-type Arabidopsis thaliana plants were freeze dried, ground with a micro-Wiley mill, and 46-68 mg (dry weight) of tissue twice extracted with $2.5 \mathrm{~mL} 80 \%$ ethanol overnight and then combined prior to drying a $3 \mathrm{ml}$ aliquot in a nitrogen stream. Sorbitol was added (to achieve $103.45 \mathrm{ng} / \mu \mathrm{L}$ injected) before extraction as an internal standard to correct for 
differences in extraction efficiency, subsequent differences in derivatization efficiency and changes in sample volume during heating. Dried extracts were dissolved in $500 \mu \mathrm{L}$ of silylationgrade acetonitrile followed by the addition of $500 \mu \mathrm{L} \quad \mathrm{N}$-methyl-Ntrimethylsilyltrifluoroacetamide (MSTFA) with 1\% trimethylchlorosilane (TMCS) (Thermo Scientific, Bellefonte, PA), and samples then heated for $1 \mathrm{~h}$ at $70^{\circ} \mathrm{C}$ to generate trimethylsilyl (TMS) derivatives (Li et al., 2012; Tschaplinski et al., 2013). After 2 days, 1- $\mu \mathrm{L}$ aliquots were injected into an Agilent Technologies Inc. (Santa Clara, CA) 5975C inert XL gas chromatograph-mass spectrometer, fitted with an Rtx-5MS with Integra-guard (5\% diphenyl/95\% dimethyl polysiloxane) $30 \mathrm{~m}$ x $250 \mu \mathrm{m}$ x $0.25 \mu \mathrm{m}$ film thickness capillary column. The standard quadrupole GC-MS was operated in the electron impact $(70 \mathrm{eV})$ ionization mode, targeting 6 full-spectrum (50-650 Da) scans per second. Gas (helium) flow was set at $1.0 \mathrm{~mL}$ per minute with the injection port configured in the splitless mode. The injection port, MS Source, and MS Quad temperatures were set to $250^{\circ} \mathrm{C}, 230^{\circ} \mathrm{C}$, and $150^{\circ} \mathrm{C}$, respectively. The initial oven temperature was held at $50^{\circ} \mathrm{C}$ for $2 \mathrm{~min}$ and was programmed to increase at $20^{\circ} \mathrm{C}$ per min to 325 ${ }^{\circ} \mathrm{C}$ and held for another $11 \mathrm{~min}$, before cycling back to the initial conditions. A total of 170 metabolite peaks were extracted using a key selected ion, characteristic $\mathrm{m} / \mathrm{z}$ fragment, rather than the total ion chromatogram, to minimize integrating co-eluting metabolites. The extracted peaks of known metabolites were scaled back up to the total ion current using predetermined scaling factors. Peaks were quantified by area integration and the concentrations were normalized to the quantity of the internal standard (sorbitol) recovered, amount of sample extracted, derivatized, and injected. A large user-created database (>1900 spectra) of mass spectral electron impact ionization (EI) fragmentation patterns of TMS-derivatized compounds, as well as the Wiley Registry 8th Edition combined with NIST 05 mass spectral database, were used to identify the metabolites of interest to be quantified. Students $t$-tests were used to test for significant differences $(\mathrm{P} \leq 0.05)$ between the mutant lines and the wild-type controls.

\subsection{Transfection of leaf protoplasts for transactivation analysis}

Leaves from 4 week-old greenhouse-grown Arabidopsis were used as a source of protoplasts. One reporter construct (promoter-luciferase) and one effector construct (35S: transcription factor) were co-transfected into protoplasts as described (Zhao et al., 2010b). A reference construct containing the Renilla luciferase gene driven by the $35 \mathrm{~S}$ promoter was also co- 
transfected to determine the transfection efficiency. Luciferase activities were determined using the dual-luciferase reporter assay system (Promega, Madison, WI). The firefly luciferase activity was calculated by normalizing against the Renilla luciferase activity in each transfection event. Data are presented as averages \pm SE of three biological replicates.

\subsection{Sample preparation for microscopy}

Wild-type and mutant plants were grown in the greenhouse. The second internodes were used for microscopic analysis. The stem was hand cut into approximately $50 \mu \mathrm{m}$ thickness slices. All samples were washed with distilled water several times and imaged in water.

\subsection{SRS microscopy}

The two-color Stimulated Raman Scattering (SRS) imaging microscope using a mode-locked $\mathrm{Nd}: \mathrm{YVO}_{4}$ laser (High Q Laser, Austria) was used to generate a 7 ps, $76 \mathrm{MHz}$ pulse train of both $1064 \mathrm{~nm}(1 \mathrm{~W}$ average power) and $532 \mathrm{~nm}(5 \mathrm{~W}$ average power) laser beams. The $1064 \mathrm{~nm}$ output was used as the Stokes light. The $532 \mathrm{~nm}$ beam was 50/50 split to pump two optical parametric oscillators (OPO) (Levante Emerald, A.P.E Angewandte Physik und Elektronik $\mathrm{GmbH}$, Berlin). The output wavelengths of the OPOs were selected at 812 and $909 \mathrm{~nm}$ to use as pump beams to induce the Stimulated Raman signal for the $2900 \mathrm{~cm}^{-1}$ carbohydrate C-H vibration and the $1600 \mathrm{~cm}^{-1}$ lignin aromatic ring vibration, respectively. All pump and Stokes beams were directed into an Olympus laser scanning microscope scanning unit (BX62WI/FV300, Olympus) and focused by a high numerical aperture water-immersion objective (UPLSApo 60X 1.20 NA W, Olympus). The light transmitted through the sample was collected by an oil-immersion condenser (1.45 NA O, Nikon). The stimulated Raman loss signals were detected by silicon PIN photodiodes (FDS1010, Thorlabs) and a lock-in amplifier (SR844, Stanford Research Systems) as previously described (Ding et al., 2012)

\subsection{Image analysis}

Intensity analysis for specific types of cell wall was performed in MATLAB (MATLAB R2012b) with user-written scripts. Multiple regions containing no cell wall components were manually selected across the image of interest, which were used to determine the background intensity. The mean background intensity plus three times background intensity standard 
deviation was used as a threshold. The program then selected pixels with intensity value above the threshold for statistical analysis. For each type of plant sample, 5 images containing $\sim 50$ cells were selected for intensity analysis. Lignin $\left(1600 \mathrm{~cm}^{-1}\right)$ and carbohydrate $\left(2900 \mathrm{~cm}^{-1}\right)$ signals in each pixel were plotted, respectively, as intensity histograms and normalized by total intensity for better comparison.

\subsection{Lignin isolation and NMR analysis}

The lignin samples for NMR spectroscopy analysis were prepared according to a slightly modified cellulolytic enzyme lignin isolation procedure as previously described (Chang et al., 1975; Holtman et al., 2004). In brief, the Arabidopsis samples from prr1 knout-out and WT lines were extracted with toluene/ethanol $(2: 1, \mathrm{v} / \mathrm{v})$ for $24 \mathrm{~h}$. The extractive-free cell walls were ballmilled using a planetary ball mill (Retsch PM 100) in a $50 \mathrm{ml} \mathrm{ZrO2}$ vessel at $600 \mathrm{rpm}$ with 10 min break after every 5 min of milling. The ball-milled powder samples were then subjected to enzyme treatment in acetic acid/ammonium acetate buffer $(\mathrm{pH} 4.8)$ with cellulase and $\beta$ glucosidase for $2 \times 48 \mathrm{~h}$ at $50{ }^{\circ} \mathrm{C}$ under continuous agitation at $200 \mathrm{rpm}$. The residue was isolated by centrifugation, washed with deionized water, and freeze dried. The enzyme-treated residue was extracted with dioxane-water $(96: 4 \mathrm{v} / \mathrm{v})$ for $24 \mathrm{~h} \mathrm{X} 2$. The mixtures were centrifuged and the supernatant was collected, roto-evaporated at $40{ }^{\circ} \mathrm{C}$ under reduced pressure, and freezedried.

NMR spectra were acquired using a Bruker Avance-III $400 \mathrm{MHz}$ spectrometer operating at a frequency of $100.59 \mathrm{MHz}$ for ${ }^{13} \mathrm{C}$ nucleus. Deuterated dimethyl sulfoxide (DMSO) was used as solvent for lignin samples. The ${ }^{13} \mathrm{C}-{ }^{1} \mathrm{H}$ HSQC correlation spectra were recorded using a Bruker standard pulse sequence ('hsqcetgpsi2') with the following acquisition parameters: 10ppm spectra width in F2 $\left({ }^{1} \mathrm{H}\right)$ dimension with 2048 data points (256 ms acquisition time), 210ppm spectra width in $\mathrm{F} 1\left({ }^{13} \mathrm{C}\right)$ dimension with 320 data points (7.6 ms acquisition time), a 1.0-s pulse delay, and a ${ }^{1} J_{C H}$ of $145 \mathrm{~Hz}$ (Moinuddin et al.; Pu et al., 2009). The number of scans were 256 for the WT and 350 for the PrR mutant. The central solvent peak $\left(\delta_{\mathrm{C}} 39.5 \mathrm{ppm} ; \delta_{\mathrm{H}} 2.5 \mathrm{ppm}\right)$ was used for chemical shift calibration. NMR data were processed using the TopSpin 2.1 (Bruker BioSpin) and MestreNova (Mestre Labs) software packages.

\subsection{DNA microarray analysis}


Total RNA was isolated from mature inflorescences of 6-week-old plants with Tri-reagent using the manufacturer's protocol (Invitrogen, http://www.invitrogen.com). RNA was cleaned and concentrated using the RNeasy MinElute Cleanup Kit (Qiagen, http://www.qiagen.com), and 500 ng of purified RNA used for microarray analysis of three biological replicates of prrl mutant and control plants. Probe labeling, hybridization and scanning were conducted according to the manufacturer's instructions (Affymetrix, http://www.affymetrix.com). Data normalization used robust multi-chip average (RMA) and the presence/absence call for each probe set was obtained from dCHIP ( $\mathrm{Li}$ and Wong, 2001). Genes with significantly different expression levels between the wild-type control and mutants were selected using associative analysis (Dozmorov and Centola, 2003), and the type-I family-wise error rate was reduced by using a Bonferronicorrected $P$-value threshold of $0.05 / N$, where $N$ represents the number of genes present on the chip. The false discovery rate was monitored and controlled by $Q$ value (false discovery rate), calculated using Extraction of Differential Gene Expression (Leek et al., 2006).

\section{Acknowledgements}

This paper is dedicated to the memory of G. Paul Bolwell. We thank Dr Yuhong Tang for assistance with DNA microarray analysis. This work was supported by the Samuel Roberts Noble Foundation and the BioEnergy Science Center, a U.S. Department of Energy Bioenergy Research Center supported by the Office of Biological and Environmental Research in the DOE Office of Science. This manuscript has been authored by a contractor of the U.S. Government under contract DE-AC05-00OR22725.

\section{Legends to figures}

Fig 1. Gene co-expression networks for Arabidopsis PrR1 and PrR2. (A) PrR1 is co-expressed with many known secondary cell wall biosynthetic genes. (B) PrR2 is co-expressed with an entirely different set of genes.

Fig 2. The PrRl promoter is regulated by the SND1 and MYB46 transcription factors in protoplast transactivation assays. A PrR1 promoter-luciferase construct and effector constructs (35S: transcription factor) were co-transfected into protoplasts, along with a Renilla luciferase gene driven by the $35 \mathrm{~S}$ promoter for correction for transfection efficiency.

Fig 3. Lignin thioacidolyisis yields are reduced in the prrl mutant. 
Fig. 4. ${ }^{13} \mathrm{C}-{ }^{1} \mathrm{H}$ HSQC spectra of lignin samples from wild type and prrl loss-of-function mutant. Each HSQC spectrum is split into two parts to expand the aromatic and aliphatic regions for clearer comparison. Lignin substructures are shown on the right.

Fig. 5. Lignin and carbohydrate distribution and contents in xylem and fiber cells as revealed by two-color Stimulated Raman Scattering (SRS) microscopy. Similar signals are seen in xylem cells between the prrl-1 mutant and wild type (A), but in fiber cells the lignin signal is lower and more narrowly distributed in the prrl-1 mutant than in the wild type (B). (C) Lignin content comparison between wild type and prrl-1 mutant. (D) Carbohydrate content comparison between wild type and prr1-1 mutant.

\section{References}

Attoumbre, J., Bienaime, C., Dubois, F., Fliniaux, M. A., Chabbert, B., Baltora-Rosset, S., 2010. Development of antibodies against secoisolariciresinol--application to the immunolocalization of lignans in Linum usitatissimum seeds. Phytochemistry 71, 1979-1987.

Berthet, S., Demont-Caulet, N., Pollet, B., Bidzinski, P., Cezard, L., Le Bris, P., Borrega, N., Herve, J., Blondet, E., Balzergue, S., Lapierre, C., Jouanin, L., 2011. Disruption of LACCASE4 and 17 results in tissue-specific alterations to lignification of Arabidopsis thaliana stems. Plant Cell 23, 1124-1137.

Binns, A. N., Chen, R. H., Wood, H. N., Lynn, D. G., 1987. Cell division promoting activity of naturally occuring dehydrodiconiferyl glucosides: Do cell wall components control cell division? Proc. Natl. Acad. Sci. USA 84, 980-984.

Bonawitz, N. D., Chapple, C., 2010. The genetics of lignin biosynthesis: connecting genotype to phenotype. Annu. Rev. Genet. 44, 337-363.

Chang, H.-M., Cowling, E. B., Brown, W., Adler, E., Miksche, G., 1975. Comparative studies on cellulolytic enzyme lignin and milled wood lignin of sweetgum and spruce. Holzforschung 29, 153-159.

Davin, L. B., Wang, H. B., Crowell, A. L., Bedgar, D. L., Martin, D. M., Sarkanen, S., Lewis, N. G., 1997. Stereoselective bimolecular phenoxy radical coupling by an auxiliary (dirigent) protein without an active center. Science 275, 362-366. 
Davis, J., Brandizzi, F., Liepman, A. H., Keegstra, K., 2010. Arabidopsis mannan synthase CSLA9 and glucan synthase CSLC4 have opposite orientations in the Golgi membrane. Plant J. 64, 1028-1037.

Ding, S. Y., Liu, Y. S., Zeng, Y. N., Himmel, M. E., Baker, J. O., Bayer, E. A., 2012. How does plant cell wall nanoscale architecture correlate with enzymatic digestibility? Science 338, 1055-1060.

Dixon, R. A., 2004. Phytoestrogens. Annu. Rev. Plant Biol. 55, 225-261.

Dozmorov, I., Centola, M., 2003. An associative analysis of gene expression array data. Bioinformatics 19, 204-211.

Hano, C., Martin, I., Fliniaux, O., Legrand, B., Gutierrez, L., Arroo, R. R., Mesnard, F., Lamblin, F., Laine, E., 2006. Pinoresinol-lariciresinol reductase gene expression and secoisolariciresinol diglucoside accumulation in developing flax (Linum usitatissimum) seeds. Planta 224, 12911301.

Hemmati, S., von Heimendahl, C. B., Klaes, M., Alfermann, A. W., Schmidt, T. J., Fuss, E., 2010. Pinoresinol-lariciresinol reductases with opposite enantiospecificity determine the enantiomeric composition of lignans in the different organs of Linum usitatissimum L. Planta Med. 76, 928-934.

Holtman, K. M., Chang, H.-M., Kadla, J. F., 2004. Solution-state nuclear magnetic resonance study of the similarities between milled wood lignin and cellulolytic enzyme lignin. J. Agric. Food Chem. 52, 720-726.

Huis, R., Morreel, K., Fliniaux, O., Lucau-Danila, A., Fenart, S., Grec, S., Neutelings, G., Chabbert, B., Mesnard, F., Boerjan, W., Hawkins, S., 2012. Natural hypolignification is associated with extensive oligolignol accumulation in flax stems. Plant Physiol. 158, 18931915.

Lee, Y., Rubio, M. C., Alassimone, J., Geldner, N., 2013. A mechanism for localized lignin deposition in the endodermis. Cell 153 402-412.

Leek, J. T., Monsen, E., Dabney, A. R., Storey, J. D., 2006. EDGE: extraction and analysis of differential gene expression. Bioinformatics 22, 507-508.

Li, C., Wong, W. H., 2001. Model-based analysis of oligonucleotide arrays: expression index computation and outlier detection. Proc. Natl. Acad. Sci. USA 98, 31-36. 
Li, Y., Tschaplinski, T. J., Engle, N. L., Hamilton, C. Y., Rodriguez Jr., M., Liao, J. C., Schadt, C. W., Guss, A. M., Yang, Y., Graham, D. E., 2012. Combined inactivation of the Clostridium cellulolyticum lactate and malate dehydrogenase genes substantially increases ethanol yield from cellulose and switchgrass fermentations. Biotechnol. for Biofuels 5, 2.

McCann, M. J., Gill, C. I., McGlynn, H., Rowland, I. R., 2005. Role of mammalian lignans in the prevention and treatment of prostate cancer. Nutr. Cancer 52, 1-14.

Moinuddin, S. G. A., Jourdes, M., Laskar, D. D., Ki, C., Cardenas, C. L., Kim, K. W., Zhang, D., Davin, L. B., Lewis, N. G., 2010. Insights into lignin primary structure and deconstruction from Arabidopsis thaliana COMT (caffeic acid O-methyl transferase) mutant Atomt1. Organic Biomol. Chem. 8, 3928-3946.

Nakashima, J., Chen, F., Jackson, L., Shadle, G., Dixon, R. A., 2008. Multi-site genetic modification of monolignol bioynthesis in alfalfa (Medicago sativa L.)- effects on lignin composition in specific cell types. New Phytol. 179, 738-750.

Nakatsubo, T., Mizutani, M., Suzuki, S., Hattori, T., Umezawa, T., 2008. Characterization of Arabidopsis thaliana pinoresinol reductase, a new type of enzyme involved in lignan biosynthesis. J. Biol. Chem. 283, 15550-15557.

Naoumkina, M. A., Zhao, Q., Gallego-Giraldo, L., Dai, X., Zhao, P. X., Dixon, R. A., 2010. Genome-wide analysis of phenylpropanoid defence pathways. Mol. Plant Pathol. 11, 829-846.

Pu, Y., Chen, F., Ziebell, A., Davison, B. H., Ragauskas, A. J., 2009. NMR characterization of C3H and HCT down-regulated alfalfa lignin. Bioenergy Res. 2 198-208.

Roberts, A. W., Roberts, E. M., Haigler, C. H., 2012. Moss cell walls: structure and biosynthesis. Front. Plant Sci. 3, 166.

Ruprecht, C., Mutwil, M., Saxe, F., Eder, M., Nikoloski, Z., Persson, S., 2011. Large-scale coexpression approach to dissect secondary cell wall formation across plant species. Frontiers in Plant Science 2:23.

Scher, J. M., Zapp, J., Becker, H., 2003. Lignan derivatives from the liverwort Bazzania trilobata. Phytochemistry 62, 769-777.

Schmidt, T. J., Hemmati, S., Klaes, M., Konuklugil, B., Mohagheghzadeh, A., Ionkova, I., Fuss, E., Wilhelm Alfermann, A., 2010. Lignans in flowering aerial parts of Linum species-chemodiversity in the light of systematics and phylogeny. Phytochemistry 71, 1714-1728. 
Tschaplinski, T. J., Standaert, R. F., Engle, N. L., Martin, M. Z., Sangha, A. K., Parks, J. M., Smith, J. C., Samuel, R., Pu, Y., Ragauskas, A. J., Hamilton, C. Y., Fu, C., Wang, Z.-Y., Davison, B. H., Dixon, R. A., Meilenz, J.R., 2013. Down-regulation of the caffeic acid $O$ methyltransferase gene in switchgrass reveals a novel monolignol analog. Biotechnology for Biofuels 5, 71.

Umezawa, T., 2003. Diversity in lignan biosynthesis. Phytochem. Rev. 2, 371-390.

Villalobos, D. P., Diaz-Moreno, S. M., Said el, S. S., Canas, R. A., Osuna, D., Van Kerckhoven, S. H., Bautista, R., Claros, M. G., Canovas, F. M., Canton, F. R., 2012. Reprogramming of gene expression during compression wood formation in pine: coordinated modulation of Sadenosylmethionine, lignin and lignan related genes. BMC Plant Biol. 12, 100.

von Heimendahl, C. B., Schafer, K. M., Eklund, P., Sjoholm, R., Schmidt, T. J., Fuss, E., 2005. Pinoresinol-lariciresinol reductases with different stereospecificity from Linum album and Linum usitatissimum. Phytochemistry 66, 1254-1263.

Wang, S., Yin, Y., Ma, Q., Tang, X., Hao, D., Xu, Y., 2012. Genome-scale identification of cellwall related genes in Arabidopsis based on co-expression network analysis. BMC Plant Biol $12,1-12$.

Weng, J. K., Chapple, C., 2010. The origin and evolution of lignin biosynthesis. New Phytol. $187,273-285$.

Zhao, Q., Dixon, R. A., 2011. Transcriptional networks for lignin biosynthesis: more complex than we thought? Trends Plant Sci. 16, 227-233.

Zhao, Q., Gallego-Giraldo, L., Wang, H., Zeng, Y., Ding, S. Y., Chen, F., Dixon, R. A., 2010a. An NAC transcription factor orchestrates multiple features of cell wall development in Medicago truncatula. Plant J. 63, 100-114.

Zhao, Q., Nakashima, J., Chen, F., Yin, Y., Fu, C., Yun, J., Shao, H., Wang, X., Wang, Z. Y., Dixon, R. A., 2013a. LACCASE is necessary and nonredundant with PEROXIDASE for lignin polymerization during vascular development in Arabidopsis. Plant Cell 25, 3976-87.

Zhao, Q., Tobimatsu, Y., Zhou, R., Pattathil, S., Gallego-Giraldo, L., Fu, C., Jackson, L. A., Hahn, M. G., Kim, H., Chen, F., Ralph, J., Dixon, R. A., 2013b. Loss of function of cinnamyl alcohol dehydrogenase 1 leads to unconventional lignin and a temperature-sensitive growth defect in Medicago truncatula. Proc. Natl. Acad. Sci. USA 110, 13660-13665. 
Zhao, Q., Wang, H., Yin, Y., Xu, Y., Chen, F., Dixon, R. A., 2010b. Syringyl lignin biosynthesis is directly regulated by a secondary cell wall master switch. Proc. Natl. Acad. Sci. USA 107, 14496-14501.

Zhong, R., Demura, T., Ye, Z. H., 2006. SND1, a NAC domain transcription factor, is a key regulator of secondary wall synthesis in fibers of Arabidopsis. Plant Cell 18, 3158-3170.

Zhong, R., Richardson, E. A., Ye, Z. H., 2007. The MYB46 transcription factor is a direct target of SND1 and regulates secondary wall biosynthesis in Arabidopsis. Plant Cell 19, 2776-2792. 
Table 1. Metabolite concentrations ( $\mu \mathrm{g} / \mathrm{g}$ DW sorbitol equivalent) of shoot biomass of Arabidopsis thaliana wild-type (WT), prr1 loss-of-function mutant (prr1), and PrR1 overexpression plants (PrR1). The average (Avg) concentration of two biological replicates per plant type is shown. * designates that the fold change is statistically significant $(\mathrm{P} \leq 0.05)$ based on Student $t$-tests. Unknowns are identified by their retention time followed by key mass-tocharge ratios $(\mathrm{m} / \mathrm{z})$.

\begin{tabular}{|c|c|c|c|c|c|}
\hline Plant type & prr1 & WT & PrR1 & $\begin{array}{l}\text { Fold } \\
\text { change }\end{array}$ & $\begin{array}{l}\text { Fold } \\
\text { change }\end{array}$ \\
\hline Metabolite & Avg & Avg & Avg & prr1/WT & PrR1/WT \\
\hline 4-hydroxyphenylethanol & 1.1 & 0.6 & 2.1 & 1.70 & 3.31 \\
\hline raffinose & 48.5 & 37.5 & 82.5 & 1.29 & 2.20 \\
\hline galactinol & 117.5 & 63.2 & 134.6 & 1.86 & 2.13 \\
\hline glutamic acid & 642.3 & 508.6 & 818.2 & 1.26 & 1.61 \\
\hline 13.53140342 & 18.5 & 15.9 & 25.3 & 1.17 & 1.60 \\
\hline maltose & 199.6 & 180.7 & 288.3 & 1.10 & 1.59 \\
\hline sinapyl aldehyde & 3.5 & 2.7 & 4.2 & 1.30 & 1.57 \\
\hline digalactopyranosylglycerol & 7.8 & 7.4 & 11.3 & 1.05 & 1.53 \\
\hline monopalmitin & 63.2 & 58.6 & 87.3 & 1.08 & 1.49 \\
\hline coniferyl aldehyde & 2.8 & 2.4 & 3.5 & 1.18 & 1.48 \\
\hline 16.53361 guaiacyl lignan & 2.5 & 3.5 & 5.0 & 0.72 & $1.42^{*}$ \\
\hline 16.48 guaiacyl lignan & 1.6 & 2.2 & 3.1 & 0.73 & $1.40 *$ \\
\hline cis-sinapic acid & 54.7 & 68.4 & 94.9 & $0.80 *$ & 1.39 \\
\hline 17.07498588558 & 0.21 & 0.32 & 0.44 & 0.67 & $1.38^{*}$ \\
\hline monostearin & 4.7 & 3.6 & 4.9 & 1.32 & 1.38 \\
\hline 16.57 guaiacyl lignan & 1.0 & 1.3 & 1.8 & 0.71 & 1.37 \\
\hline
\end{tabular}




\begin{tabular}{|c|c|c|c|c|c|}
\hline 17.17320 guaiacyl lignan & 2.2 & 3.3 & 4.5 & 0.68 & $1.37 *$ \\
\hline syringic acid-4-O-glucoside & 4.6 & 5.9 & 7.9 & 0.78 & 1.36 \\
\hline trans-sinapic acid & 207.1 & 258.9 & 351.3 & $0.80 *$ & $1.36^{*}$ \\
\hline coniferyl alcohol & 5.5 & 5.8 & 7.8 & 0.95 & 1.35 \\
\hline alpha-tocopherol & 1.0 & 1.0 & 1.3 & 1.00 & 1.35 \\
\hline galactopyranosylglycerol & 41.1 & 33.2 & 43.8 & 1.24 & 1.32 \\
\hline p-toluic acid & 3.6 & 1.6 & 2.1 & 2.21 & 1.31 \\
\hline 14.73267 guaiacyl lignan & 1.9 & 2.1 & 2.7 & 0.92 & 1.30 \\
\hline a,a-diglycerol-phosphate & 56.1 & 54.7 & 70.8 & 1.03 & 1.29 \\
\hline xylitol & 10.6 & 9.2 & 11.8 & 1.15 & 1.28 \\
\hline 1-linoleyl-rac-glycerol & 11.4 & 11.1 & 14.3 & 1.03 & 1.28 \\
\hline dehydroconiferyl alcohol & 0.19 & 0.29 & 0.36 & 0.65 & $1.26^{*}$ \\
\hline gamma-aminobutyric acid & 328.4 & 291.2 & 367.1 & 1.13 & 1.26 \\
\hline vanillic acid & 3.3 & 3.5 & 4.3 & 0.95 & 1.25 \\
\hline vanillic acid-4-O-glucoside & 46.6 & 52.3 & 65.4 & 0.89 & $1.25^{*}$ \\
\hline vanillin & 1.9 & 2.1 & 2.6 & 0.88 & 1.24 \\
\hline threonic acid & 15.7 & 12.8 & 15.9 & 1.22 & 1.24 \\
\hline trehalose & 152.2 & 136.6 & 169.0 & 1.11 & 1.24 \\
\hline alpha-linolenic acid & 167.9 & 170.4 & 210.0 & 0.99 & 1.23 \\
\hline alanine & 610.9 & 701.0 & 862.8 & 0.87 & 1.23 \\
\hline linoleic acid & 94.6 & 97.7 & 120.2 & 0.97 & 1.23 \\
\hline arachidic acid & 3.7 & 4.2 & 5.2 & 0.88 & 1.23 \\
\hline 18.08498588558 & 0.21 & 0.28 & 0.35 & 0.74 & $1.23 *$ \\
\hline glycerol-2-phosphate & 13.6 & 14.3 & 17.4 & 0.95 & 1.22 \\
\hline alpha-aminoadipic acid & 18.8 & 17.5 & 21.4 & 1.07 & 1.22 \\
\hline shikimic acid & 1029.8 & 976.0 & 1188.1 & 1.06 & 1.22 \\
\hline
\end{tabular}




\begin{tabular}{|c|c|c|c|c|c|}
\hline fructose & 170.4 & 166.3 & 202.2 & 1.03 & 1.22 \\
\hline glycolic acid & 21.9 & 22.1 & 26.7 & 0.99 & 1.21 \\
\hline ribitol & 35.0 & 35.9 & 43.3 & 0.97 & 1.21 \\
\hline salicylic acid-2-O-glucoside & 5.8 & 5.2 & 6.2 & 1.12 & 1.20 \\
\hline ferulic acid & 2.8 & 3.0 & 3.6 & 0.95 & 1.20 \\
\hline secoisolariciresinol & 2.1 & 2.2 & 2.6 & 0.97 & 1.16 \\
\hline ethyl-phosphate & 195.2 & 209.7 & 242.4 & 0.93 & 1.16 \\
\hline docosanoic acid & 3.5 & 4.2 & 4.8 & 0.85 & 1.15 \\
\hline serine & 552.5 & 606.5 & 699.2 & 0.91 & 1.15 \\
\hline citramalic acid & 31.9 & 27.6 & 31.7 & 1.16 & 1.15 \\
\hline 2-hydroxyglutaric acid & 30.7 & 26.5 & 30.4 & 1.16 & 1.15 \\
\hline 5-hydroxyferulic acid-glucoside & 0.3 & 0.5 & 0.5 & 0.63 & 1.15 \\
\hline adenine & 10.8 & 11.5 & 13.2 & 0.94 & 1.15 \\
\hline 5-hydroxyferulic acid & 0.8 & 1.0 & 1.1 & 0.86 & 1.14 \\
\hline cholesterol & 6.2 & 5.6 & 6.3 & 1.10 & 1.13 \\
\hline tetracosanoic acid & 15.4 & 19.4 & 21.8 & 0.79 & 1.13 \\
\hline ascorbic acid & 7.7 & 8.3 & 9.3 & 0.93 & 1.12 \\
\hline maleic acid & 67.4 & 69.5 & 78.1 & 0.97 & 1.12 \\
\hline glycerol & 529.6 & 529.1 & 590.8 & 1.00 & 1.12 \\
\hline gamma-tocopherol & 1.3 & 1.4 & 1.5 & 0.92 & 1.11 \\
\hline oleic acid & 4.8 & 5.6 & 6.2 & 0.86 & 1.11 \\
\hline phosphoethanolamine & 14.4 & 15.3 & 16.8 & 0.94 & 1.09 \\
\hline ethanolamine & 2136.7 & 2576.2 & 2818.1 & $0.83 *$ & 1.09 \\
\hline butyric acid & 8.7 & 9.2 & 10.0 & 0.94 & 1.09 \\
\hline arbutin & 1.9 & 2.1 & 2.3 & 0.91 & 1.09 \\
\hline galactose & 390.0 & 445.0 & 482.9 & 0.88 & 1.09 \\
\hline
\end{tabular}




\begin{tabular}{|c|c|c|c|c|}
\hline glutamine & 550.3 & 771.9 & 836.2 & $0.71 *$ \\
\hline aspartic acid & 1042.3 & 1146.2 & 1240.7 & 0.91 \\
\hline B-alanine & 79.6 & 102.5 & 110.2 & $0.78 *$ \\
\hline erythronic acid & 180.4 & 178.0 & 190.8 & 1.01 \\
\hline fumaric acid & 4186.3 & 4022.3 & 4300.3 & 1.04 \\
\hline myoinositol-2-phosphate & 20.1 & 20.8 & 22.2 & 0.97 \\
\hline stigmastanol & 6.2 & 6.3 & 6.7 & 0.99 \\
\hline phenylalanine & 76.8 & 82.8 & 87.9 & 0.93 \\
\hline $\begin{array}{l}17.28456162 \text { syringyl-guaiacyl } \\
\text { lignan }\end{array}$ & 6.5 & 6.9 & 7.3 & 0.95 \\
\hline leucine & 41.4 & 35.5 & 37.6 & 1.16 \\
\hline syringaldehyde & 2.2 & 2.7 & 2.8 & 0.82 \\
\hline succinic acid & 197.8 & 206.8 & 217.7 & 0.96 \\
\hline palmitic acid & 197.4 & 180.0 & 188.6 & 1.10 \\
\hline glycerol-1/3-phosphate & 177.0 & 182.0 & 190.0 & 0.97 \\
\hline adenosine & 29.2 & 35.4 & 36.7 & 0.83 \\
\hline glucose & 1410.1 & 1528.1 & 1581.5 & 0.92 \\
\hline campesterol & 63.4 & 72.3 & 74.7 & 0.88 \\
\hline erythronic acid-gamma-lactone & 203.7 & 200.7 & 207.5 & 1.01 \\
\hline phytol & 2253.1 & 2555.9 & 2629.1 & 0.88 \\
\hline sitosterol & 195.3 & 198.4 & 203.0 & 0.98 \\
\hline 4-hydroxybenzoic acid & 5.3 & 5.7 & 5.8 & 0.94 \\
\hline 3,4-dihydroxybenzoic acid & 2.5 & 2.3 & 2.4 & 1.06 \\
\hline sinapoyl-malic acid & 1.6 & 3.2 & 3.2 & $0.50 *$ \\
\hline 17.56453468209 & 0.29 & 0.40 & 0.41 & $0.71^{*}$ \\
\hline isoleucine & 47.0 & 48.1 & 48.7 & 0.98 \\
\hline
\end{tabular}




\begin{tabular}{|c|c|c|c|c|c|}
\hline citric acid & 473.1 & 538.2 & 544.5 & 0.88 & 1.01 \\
\hline $\begin{array}{l}\text { 1-(indol-3-yl)- } \\
\text { piperidinocyclopropane }\end{array}$ & 3.7 & 3.5 & 3.6 & 1.04 & 1.01 \\
\hline quinic acid & 0.4 & 0.5 & 0.5 & 0.82 & 1.01 \\
\hline threonine & 367.7 & 487.3 & 487.3 & 0.75 & 1.00 \\
\hline B-amyrin & 22.9 & 23.3 & 23.2 & 0.98 & 1.00 \\
\hline sucrose & 2513.4 & 2509.0 & 2485.8 & 1.00 & 0.99 \\
\hline myoinositol & 0.5 & 0.5 & 0.5 & 0.95 & 0.99 \\
\hline 2-hydroxy-2-propenoic acid & 18.9 & 24.7 & 24.5 & 0.76 & 0.99 \\
\hline tyrosine & 25.3 & 22.9 & 22.6 & 1.11 & 0.99 \\
\hline cis-sinapic acid-4-O-glucoside & 0.7 & 0.8 & 0.8 & 0.88 & 0.98 \\
\hline 2-hydroxy-3-methylvaleric acid & 176.2 & 209.9 & 204.7 & 0.84 & 0.98 \\
\hline valine & 196.0 & 236.4 & 226.3 & 0.83 & 0.96 \\
\hline lysine & 52.9 & 51.5 & 48.9 & 1.03 & 0.95 \\
\hline 9.91114281354256184 & 9.0 & 11.6 & 11.0 & $0.78 *$ & 0.95 \\
\hline asparagine & 66.3 & 90.8 & 86.1 & 0.73 & 0.95 \\
\hline 1-hexacosanol & 11.9 & 14.4 & 13.5 & 0.83 & 0.94 \\
\hline malic acid & 724.3 & 785.0 & 732.7 & 0.92 & 0.93 \\
\hline kaempferol & 2.2 & 3.8 & 3.5 & 0.58 & 0.93 \\
\hline 15-nonacosanone & 12.1 & 17.8 & 16.5 & 0.68 & 0.93 \\
\hline benzoic acid & 22.6 & 23.3 & 21.4 & 0.97 & 0.92 \\
\hline salicylic acid & 3.4 & 6.2 & 5.7 & 0.55 & 0.92 \\
\hline aconitic acid & 5.7 & 7.5 & 6.9 & 0.76 & 0.91 \\
\hline tryptophan & 30.7 & 29.4 & 26.6 & 1.04 & 0.90 \\
\hline glyceric acid & 231.6 & 281.3 & 253.9 & 0.82 & 0.90 \\
\hline stearic acid & 58.9 & 48.5 & 42.4 & 1.21 & 0.87 \\
\hline
\end{tabular}


pinoresinol

lactic acid

nonacosane

3-phosphoglyceric acid $\begin{array}{lllll}0.19 & 0.04 & 0.03 & 4.79 * & 0.85\end{array}$

$\begin{array}{lllll}19.7 & 13.1 & 10.3 & 1.50 & 0.79\end{array}$

$\begin{array}{lllll}20.0 & 32.9 & 25.7 & 0.61 & 0.78\end{array}$

$\begin{array}{lllll}5.4 & 8.4 & 6.5 & 0.64 & 0.77\end{array}$ 


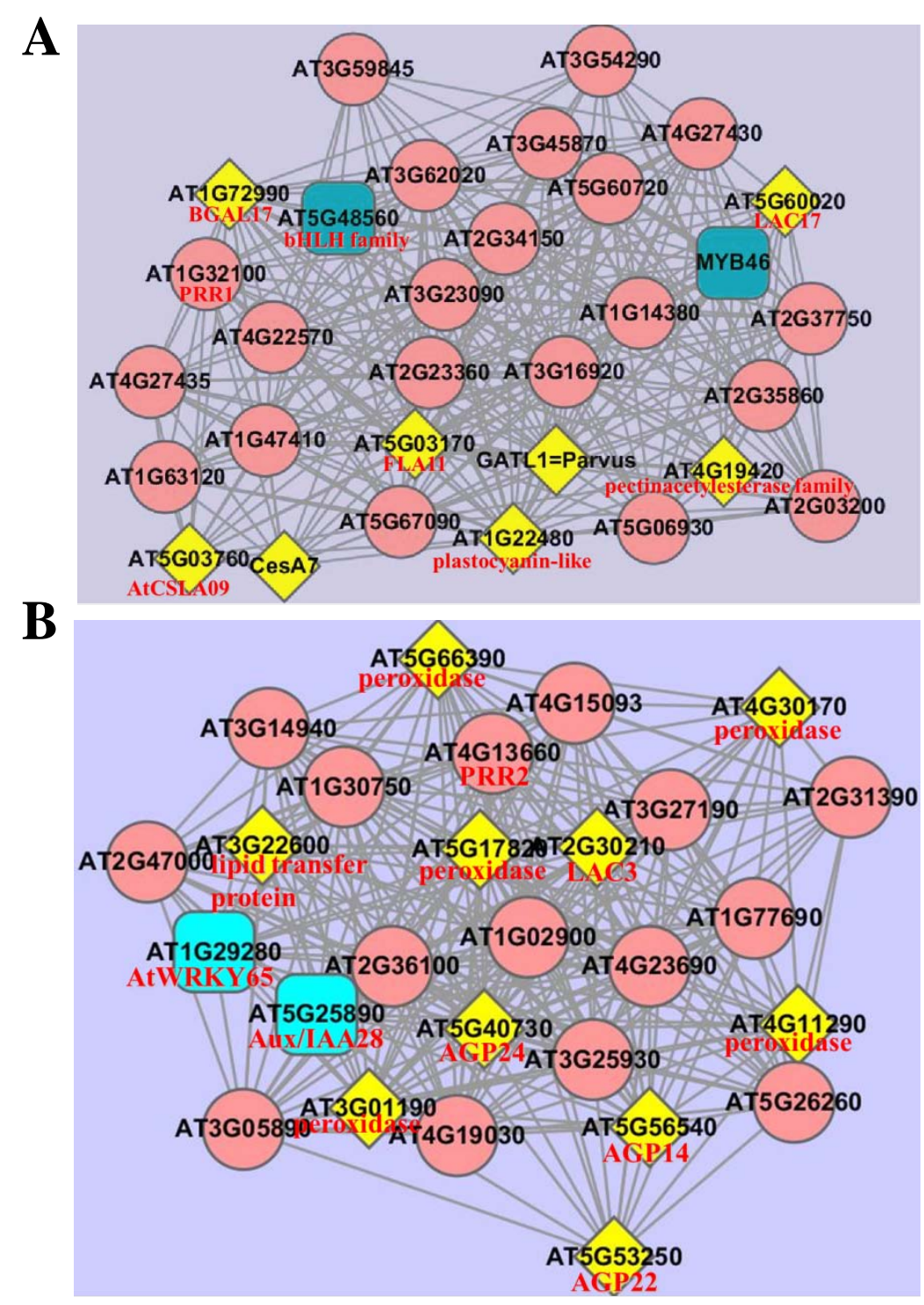

Fig 1. Gene co-expression networks for Arabidopsis PrR1 and PrR2. (A) PrR1 is coexpressed with many known secondary cell wall biosynthetic genes. (B) PrR2 is coexpressed with an entirely different set of genes. 


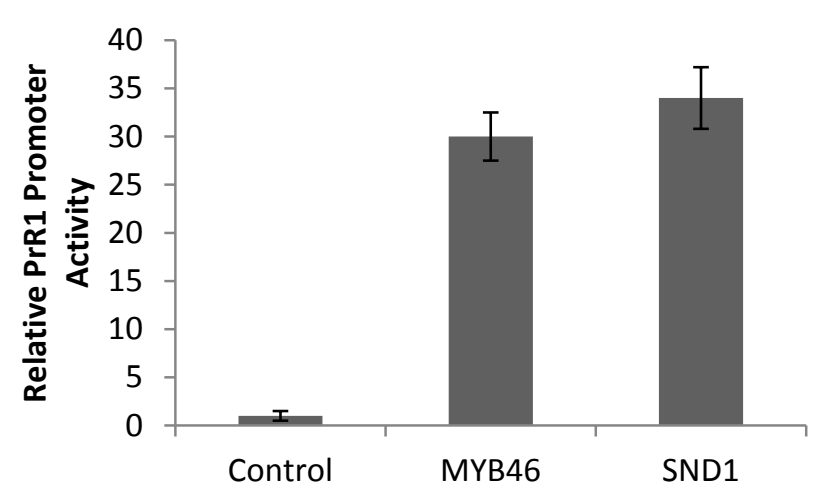

Fig 2. The PrR1 promoter is regulated by the SND1 and MYB46 transcription factors in protoplast transactivation assays. 


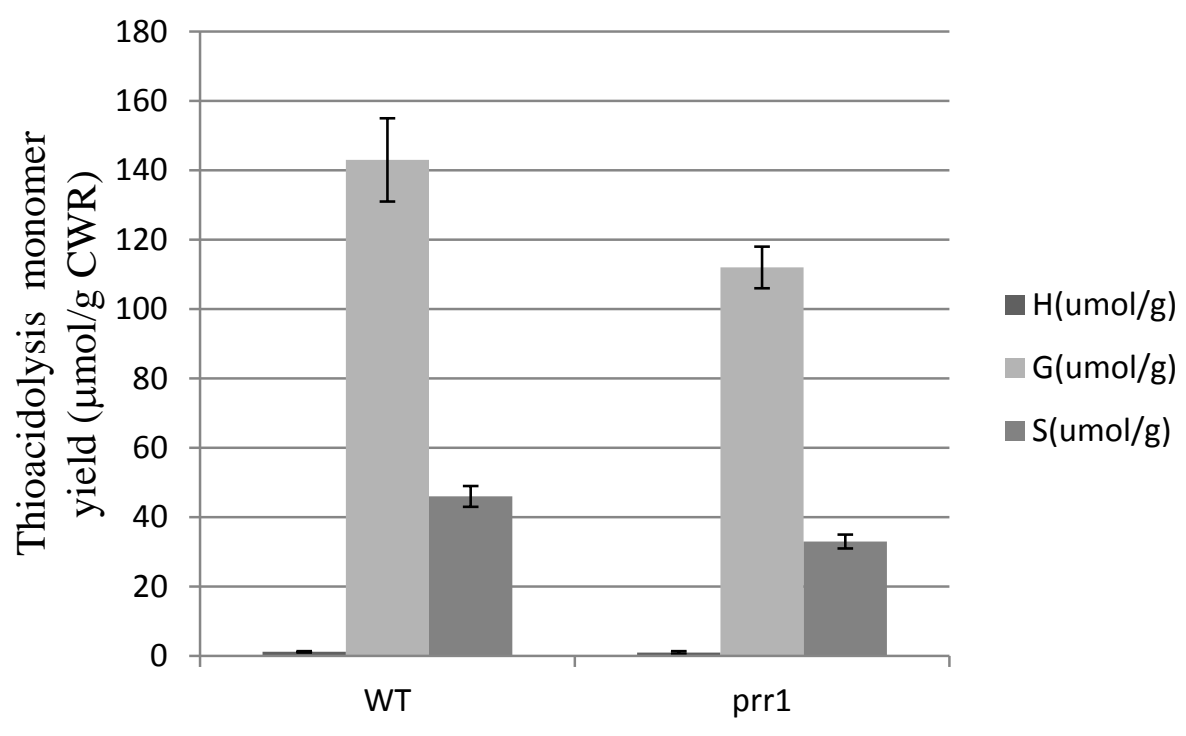

Fig 3. Lignin thioacidolyisis yields are reduced in the prr1 mutant. CWR, cell wall residue. 
Lignin from wild-type plants

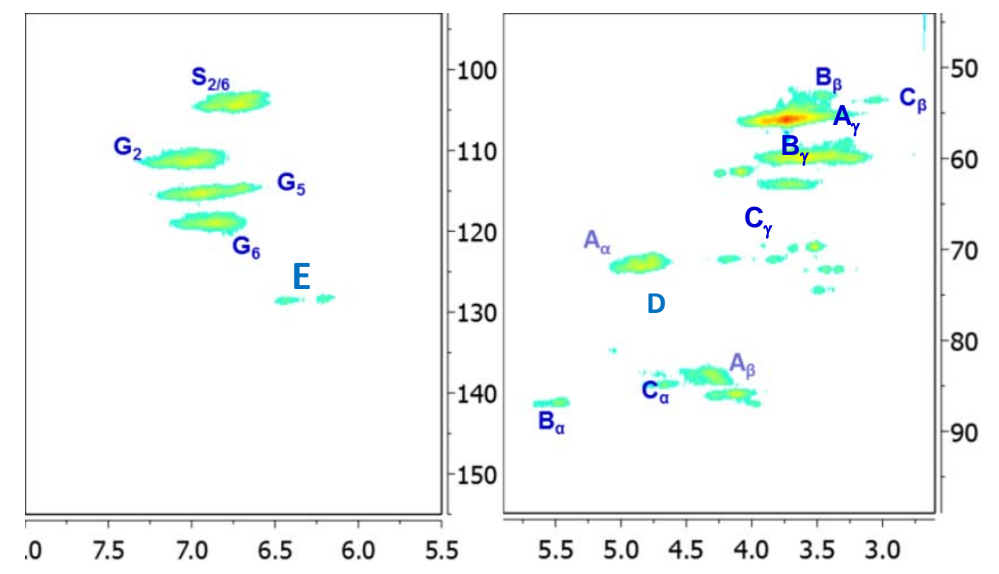
A: $\beta-O-4$
B: phenylcoumaran
C: resinol

Lignin from prr1-1 mutant plants
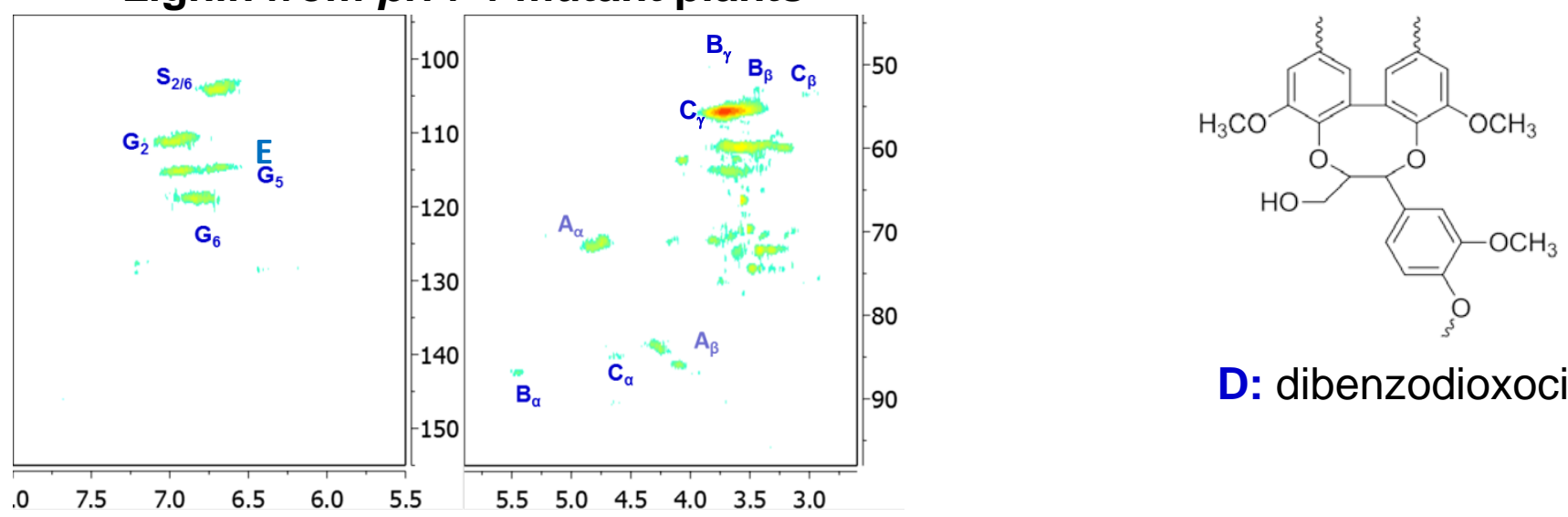

D: dibenzodioxocin E: cinnamyl alcohol

Fig. 4. ${ }^{13} \mathrm{C}-{ }^{1} \mathrm{H}$ HSQC spectra of lignin samples from wild type and prr1 loss-of-function mutant. Each HSQC spectrum is split into two parts to expand the aromatic and aliphatic regions for clearer comparison. Lignin substructures are shown on the right. 
A
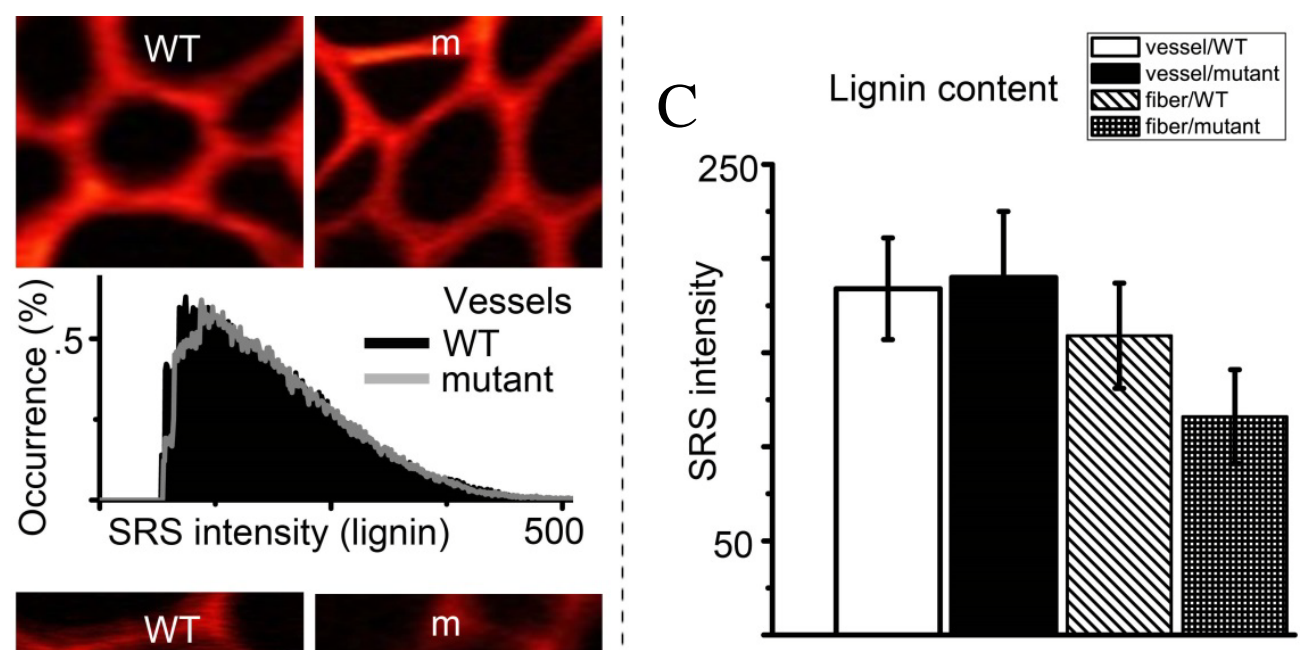

B
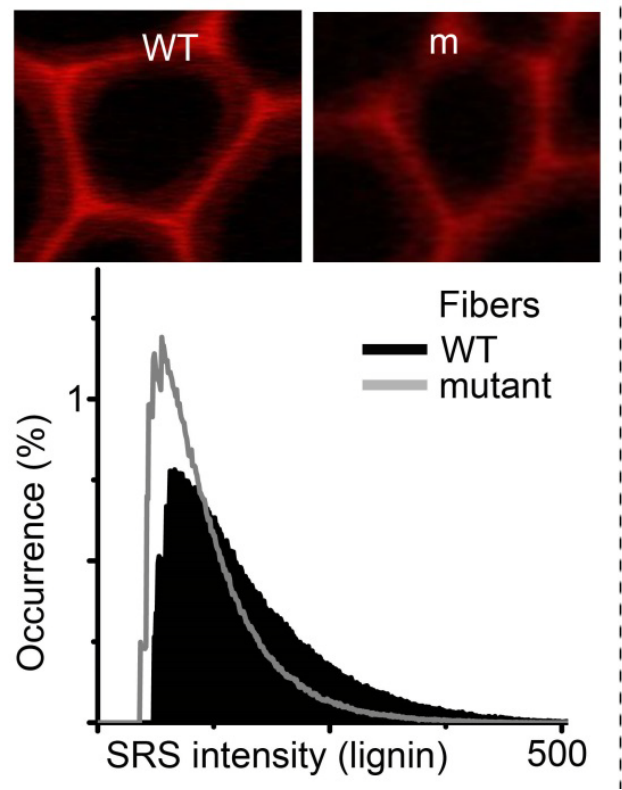
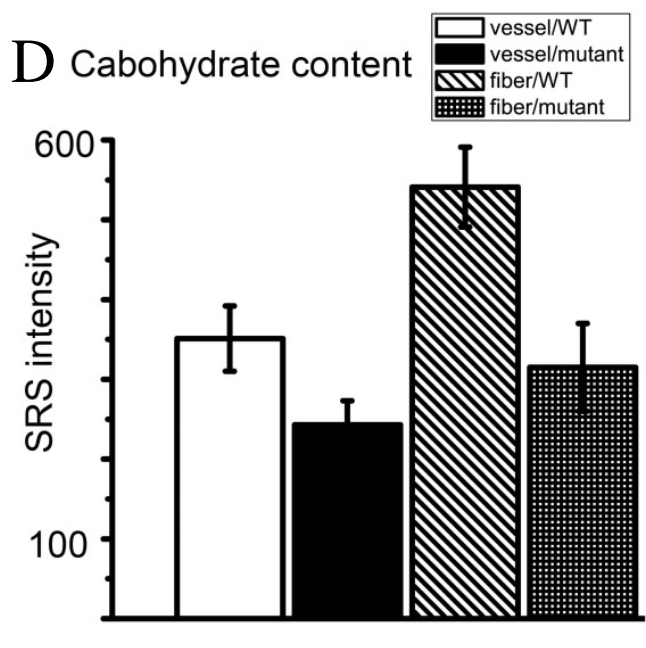

Fig. 5. Lignin distribution and contents in xylem and fiber cells as revealed by two-color Stimulated Raman Scattering (SRS) imaging microscopy. Similar signals are seen in xylem cells between the mutant and wild type (A), but in fiber cells the lignin signal is lower and more narrowly distributed in the mutant than in the wild type (B). (C) Lignin content comparison between wild type and mutant. (D) Carbohydrate content comparison between wild type and mutant. 


\section{Graphical Abstract}

\section{Pinoresinol reductase 1 impacts lignin distribution during secondary cell wall biosynthesis in Arabidopsis}

Qiao Zhao, Yining Zeng, Yanbin Yin, Yunqiao Pu, Lisa A. Jackson, Nancy L. Engle, Madhavi Z. Martin, Timothy J. Tschaplinski, Shi-You Ding, Arthur J. Ragauskas, and Richard A. Dixon

Loss of function of the gene encoding pinoresinol reductase 1 , which is co-expressed with cell wall biosynthetic genes in Arabidopsis thaliana, not only impairs accumulation of lignans in stem tissue, but also alters lignin structure and reduces accumulation of lignin, particularly in interfascicular fibers.

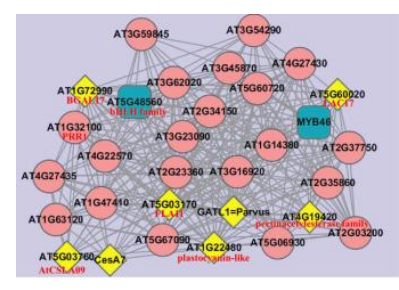

